Article

\title{
Attribution and Effectiveness of Cause-Related Marketing: The Interplay between Cause-Brand Fit and Corporate Reputation
}

\author{
Anran Zhang ${ }^{1, *}$, Alex Scodellaro ${ }^{2} \mathbb{D}$, Bo Pang ${ }^{2}$, Hui-Yi Lo ${ }^{3} \mathbb{D}$ and Zhengliang Xu ${ }^{1}$ \\ 1 School of Management, Jilin University, Changchun 130022, China; zlxu@jlu.edu.cn \\ 2 Social Marketing @ Griffith, Griffith University, Brisbane, QLD 4111, Australia; \\ a.scodellaro@griffith.edu.au (A.S.); b.pang@griffith.edu.au (B.P.) \\ 3 Department of Marketing, National Chung Hsing University, Taichung 402, Taiwan; \\ hyl@dragon.nchu.edu.tw \\ * Correspondence: zhangar16@mails.jlu.edu.cn; Tel.: +61-452-481-487
}

Received: 19 September 2020; Accepted: 5 October 2020; Published: 10 October 2020

check for updates

\begin{abstract}
In cause-related marketing (CRM) programs, the fit between the cause and brand is an important factor influencing consumer perceptions and behavior. However, the literature demonstrates that there is disagreement regarding the effect of cause-brand fit on consumer responses with varying corporate reputation. This study aims to examine the influence of cause-brand fit on consumer attitudes, attributed company motives, and the moderating role of corporate reputation. With a two (fit: high/low) by three (reputation: low/medium/high) experimental study, we reveal that consumers hold positive attitudes toward companies that engage in CRM campaigns. The effect of cause-brand fit on consumer-attributed company motives is moderated by corporate reputation. For low-reputation companies, a high cause-brand fit CRM campaign resulted in consumers attributing more negative motives to companies than low-fit campaigns. The opposite was true for medium-reputation companies. Meanwhile, high-reputation companies with a high cause-brand fit elicit greater value-driven attributed motives from consumers than other motives. Recommendations for implementing CRM programs and for future research are discussed.
\end{abstract}

Keywords: cause-related marketing; cause-brand fit; corporate reputation; attributed motives; consumer attitudes

\section{Introduction}

Companies and private organizations have been viewed as significant contributors to many contemporary environmental, social, and economic problems afflicting society, i.e., sustainability [1]. Today, society expects not only performance from companies but also ethical and sustainable conduct [2]; consumers in the 21st century are increasingly aware of corporate social responsibility (CSR) practices [3]. In fact, consumers want products to be produced and sold in an environmentally friendly way that follows ethical standards [4]; technological developments have provided consumers with greater control over the information they receive and share, especially in the online environment [5]. In response, many companies have repurposed CSR into a means of gaining a competitive advantage [6] and promote socially responsible efforts by associating with social causes, which is known as cause-related marketing (CRM). CRM refers to the process of formulating and implementing marketing activities in which a firm commits to donating a specific amount to a non-profit organization (NPO) or social cause when customers purchase their products [7]. This marketing approach has been proven to be capable of benefitting the company, the consumers, and society simultaneously, and an effective strategy for companies to promote sustainability with. According to the IEG Sponsorship Spending 
Report (2019), CRM-generated sponsorship has increased from USD 630 million [8] to USD 2.23 billion (IEG 2019) in the last two decades. The benefits for the company include the opportunity to uniquely position the brand [9], increasing sales and market share [10], establishing long-term customer relationships (e.g., customer satisfaction, loyalty, and repurchase) [11], and enhancing corporate image and reputation $[12,13]$. Indeed, CRM has become a CSR practice widely adopted by companies [14], and academic reviews of CRM have gained recent interest [15-17].

Despite these benefits, CRM activities incongruent with the brand can invoke consumer skepticism toward the motives underlying a company's CSR initiatives [18]. Moreover, when company reputation is questioned, skepticism of CRM campaigns may be amplified [19], through which a lack of trust may cause negative consumer reactions to CSR initiatives [20-22]. Meanwhile, successful CRM is considered to result in consumer loyalty to cause-related products or services, being the result of an appropriate "fit" between the corporate branding and associated social causes [23,24]. Consumer perceptions of CRM are thought to depend not only on demographic factors including gender, age, education, and household income, but also psychographic factors such as systems of values, culture, and the degree of trust in the company [25]. Many studies highlight positive consumer responses to firms with high cause-brand fit [26,27], and others reveal negative outcomes for low cause-brand fit [28]. Although greater congruency between the perceived interests of the brand and cause has been found to positively increase consumer attitudes [27,29], and minimize consumer skepticism [14,30], many researchers reveal conflicting results for the mediating effects of fit on attitudes and purchase intentions. Indeed, some research suggests that cause-brand fit does not play a significant role [31,32] or that lower congruency may sometimes result in better CSR outcomes [33-35]. For example, an experiment by Ellen et al. (2006) [35] found an insignificant difference between a moderate and a high degree of cause-brand fit in relation to purchase intent. Later findings by Lafferty (2007) [31] found that the fit (poor/good) between the cause and the brand did not affect consumer attitudes and purchase intentions regardless of the level of corporate credibility (low/moderate/high). Furthermore, the specific characteristics of the CRM program (e.g., the donation amount, cause type, and message framing) have shown positive outcomes, but mixed effects are persistent.

Recent research shows that consumer perceptions strongly affect a company's reputation, where those engaging in CSR are considered more accepted and credible [36,37]. Moreover, this reputation affects how CSR initiatives are perceived by consumers [38], because of their evaluations of the CRM communication efforts by using existing knowledge and prior attitudes about the company to process the new information [39-41]. Recent research exploring the mechanisms of consumer reactions to CRM has measured such factors and their influences on consumer perception and behavioral intentions [15]. However, inconsistencies arise within the consideration of corporate reputation and cause-brand fit simultaneously as determinants for CRM effectiveness. For example, an experiment conducted by Lafferty (2007) [31] found that the fit between the cause and the brand did not affect consumer attitudes and purchase intentions, regardless of the level of corporate reputation. Meanwhile, Elving (2013) [41] found that cause-brand fit can affect consumer attitudes in a different way when varying the corporate reputation. The study found that a cause-brand fit strategy alters individual reactions to a company from negative to positive but does not affect individual attitudes if the corporate reputation is good. For these reasons, corporate reputation is considered a key influencing factor as consumers evaluate company CRM efforts.

Consumer perceptions depend, to some degree, on the effectiveness of the companies' CRM communications [42], which have even been shown to vary based on the characteristics of the medium [43]. One critical element for the success of these communications is the perception consumers have of the company's commitment toward a social cause [44,45]. In fact, Yoon et al. (2006) [46] found that if a company is not able to gain trust in its sincere motives, the desired effects of CSR efforts become unlikely. Research suggests that whilst CRM efforts communicating a firm's high cause-brand fit or intrinsic (other-focused) motives is most effective [44,47-52], consumers understand the responsibility firms have to their shareholders to make a profit [53], and stakeholders may even appreciate the extrinsic (self-focused) motives involved [18,50,54,55]. The existing empirical evidence has shown that these types of motivations attributed to companies by consumers are partially affected by the 
perceived level of cause-brand fit [18,35]. In addition to attributed motives, the current evidence base varies widely regarding consumer responses to CRM campaigns, including attitudes [56] and purchase intentions [17].

Thus, this paper aims are three fold: (i) to empirically examine the influence of cause-brand fit on consumer evaluation (attitudes toward the company) and perception (attributed company's motive), (ii) to examine the influence of consumer perceptions of different company motives on their further attitudes, and (iii) to explore the moderating role of corporate reputation in affecting the effectiveness of CRM strategies. Thus, this paper contributes to the literature by experimentally examining the perceived motives of company CRM initiatives nested in a comprehensive model. Insights generated from this model will help managers to better plan and execute their CRM activities in order to effectively achieve positive outcomes for the company and the social cause, and ultimately promote economic, environmental, and social sustainability.

\section{Conceptual Framework}

\subsection{Consumer Responses to CRM}

The great interest firms have in adopting CRM lies in its effectiveness in generating positive consumer attitudes and increasing purchase intentions [57,58]. According to Brown and Dacin (1997) [39], an organization's actions and operations are one thing, and the consumer perceptions of those actions are another. As such, many studies investigate consumer behavior with CRM and develop useful models to explain such behaviors [59-63]. More specifically, the theory of planned behavior claims the most immediate and important predictor of consumer behavior is intention [64]. Attitudes are therein defined as the overall evaluation of the favorableness or unfavorableness of the outcomes of a behavior [64], with research consistently suggesting that attitude is a strong, direct, and positive predictor of intention [65]. In this way, the cognitive and affective characteristics of CRM communications evoke emotional responses in consumers that influence their attitudes and, therefore, their behavioral intentions [66]. Interestingly, psychology research has often demonstrated that negative information has a stronger impact on people's attitudes and impressions than positive information $[67,68]$, where factors such as corporate reputation and attributed motives may work to reduce consumer skepticism [41]. Therefore, this study attempts to build on the existing knowledge of consumer behavior and examine relationships between consumer perceptions, corporate reputation, and cause-brand fit, and to develop a model using consumer attitude as the factor of interest to be investigated.

\subsection{The Role of Cause-Brand Fit}

The key to successful CRM is consumer loyalty to cause-related products, being the prerequisite for corporate support to a social cause $[47,62]$. Perceived cause-brand fit has been defined as the degree of similarity and compatibility between a company and its efforts to address environmental and/or social problems [69]. Previous studies have shown that the companies that undertake CRM efforts with a high fit with their main business activities are better regarded by consumers [14,24,27]. Theoretical explanations of consumer behavior with CRM efforts have been approached through various perspectives in the literature [70]. In particular, cue congruency theory (also known as consistency theory) has been most frequently adopted to explain the relationships between cause-brand fit and other variables [31,71]. In this paradigm, Thomas et al. (2011) [72] suggests that effective CRM communicating the alignment of social with business actions allows consumers to recognize this compatibility and, therefore, regard them as more credible. Similarly, Becker-Olsen et al. (2006) [28] confirmed that when the fit between the company and the social cause was low, the consumer felt that the company was less credible. However, many researchers reveal conflicting results for the mediating effects of fit on attitudes and purchase intentions [31,32], and some even claim that lower congruency may result in better CSR attitudinal outcomes [33-35,54]. Attempts to address these mixed results have seen researchers identify components within cause-brand congruency such as natural 
and created fit [73], conceptual and perceptual fit [14], and functional and image fit [74]. Despite this, uni-dimensional conceptions of cause-brand congruency are still investigated in relation to corporate, reputation, and consumer attitudes [31]. Therefore, we propose the following hypothesis:

H1. Cause-brand fit is positively related with consumer attitudes toward the company.

\subsection{Attributed Company Motives}

According to attribution theory [75], consumers would attribute company motives for the CRM, which refers to the inferences that consumers make about the reasons for the company's CRM campaign [29,76]. Previous research has discussed the role of inferred motives in affecting consumer evaluation of the company and intention to participate in the CRM campaign [15]. However, the majority of this research into how individuals attribute firm motives has primarily focused on two opposing constructs-namely, benefit to those external to the firm (i.e., altruistic, or other-centered) versus benefit to the firm itself (i.e., egoistic, or self-centered) [29,30,44]. Hemingway and Maclagan (2004) [77] added complexity by classifying a third attributable motive where firms meet societal expectations and stakeholder expectations (i.e., stakeholder-driven). Ellen et al. (2006) [35], with an interview-based qualitative study, found that consumers differentiated four types of motives of companies' CSR efforts: other-centered motives that are value driven and stakeholder driven and self-centered motives that are strategic and egoistic [35]. CRM is one type of CSR campaign related to corporate donations [78]. Thus, we predicted that consumers would attribute these four motives to companies' CRM campaigns.

The cause-brand fit of CRM could influence consumers' attributed company motives, which would further influence their attitudes toward the company [14,47]. Previous research has found that a high cause-brand fit could lead to positive consumer attribution, while a low fit would result in negative consumer attribution because of the inconsistencies with consumer expectations [14,28]. For example, Kuo and Rice (2015) [14] found that the congruence between firm and cause was positively related with consumers attributing other-serving motives and was negatively related with self-serving motives, and altruistic and self-serving motives, furthermore, had positive and negative effects on consumer reactions, respectively [29]. Differentiating between the four motives, Ellen et al. (2006) [35] found that consumers would respond positively when they judged a company's CSR efforts as value driven and strategic while responding negatively when the CSR efforts were perceived as stakeholder driven or egoistic. That is, a value-driven motive and strategic motive are positive attributions, whereas stakeholder-driven and egoistic motives are negative attributions for further consumer evaluation for the company. Thus, we proposed the following hypotheses:

H2. High cause-brand fit leads to consumers attributing more positive company motives: (a) value-driven motives; (b) strategic motives.

H3. Low cause-brand fit leads to consumers attributing more negative company motives: (a) stakeholder-driven motives; (b) egoistic motives.

H4. Consumer attitudes toward a company are positively related with (a) value-driven motives and (b) strategic motives.

H5. Consumer attitudes toward a company are negatively related with (a) stakeholder-driven motives and (b) egoistic motives.

\subsection{Corporate Reputation as a Moderator}

Corporate reputation is the result of all the perceptions that individuals have of a company [41]. Fombrun (1996) [79] (p. 72) defined it as the "perceptual representation of a company's past actions and future prospects that describe the firm's overall appeal to all of its key constituent when compared with other leading rivals". Many studies have expressed the ability of CRM activities to increase corporate reputation [15]. Looking closer, reputation is also one of the most important 
elements of persuasive messages and plays a key role in influencing consumer-attributed motives and attitudes [41]. More specifically, Elving (2013) [41] found that cause-brand fit can have positive, negative, or nonsignificant effects on consumer purchase intentions when mediating company reputation. With regard to consumer attitudes, the study found that a cause-brand fit strategy alters an individual's reaction to a company from negative to positive but does not affect an individual's attitude if the corporate reputation is good. When consumers are faced with CRM communications, their prior knowledge about the company plays an important role in affecting their perception of the new campaign/activity, subsequent evaluation, and even behavior [40]. Thus, corporate reputation would function as a moderator to affect the effect of cause-brand fit on consumer-attributed motives and attitudes toward a company. We proposed the following hypothesis:

H6. Corporate reputation has a moderating effect on the whole model.

In summary, we proposed the following theoretical research model for this study (Figure 1).

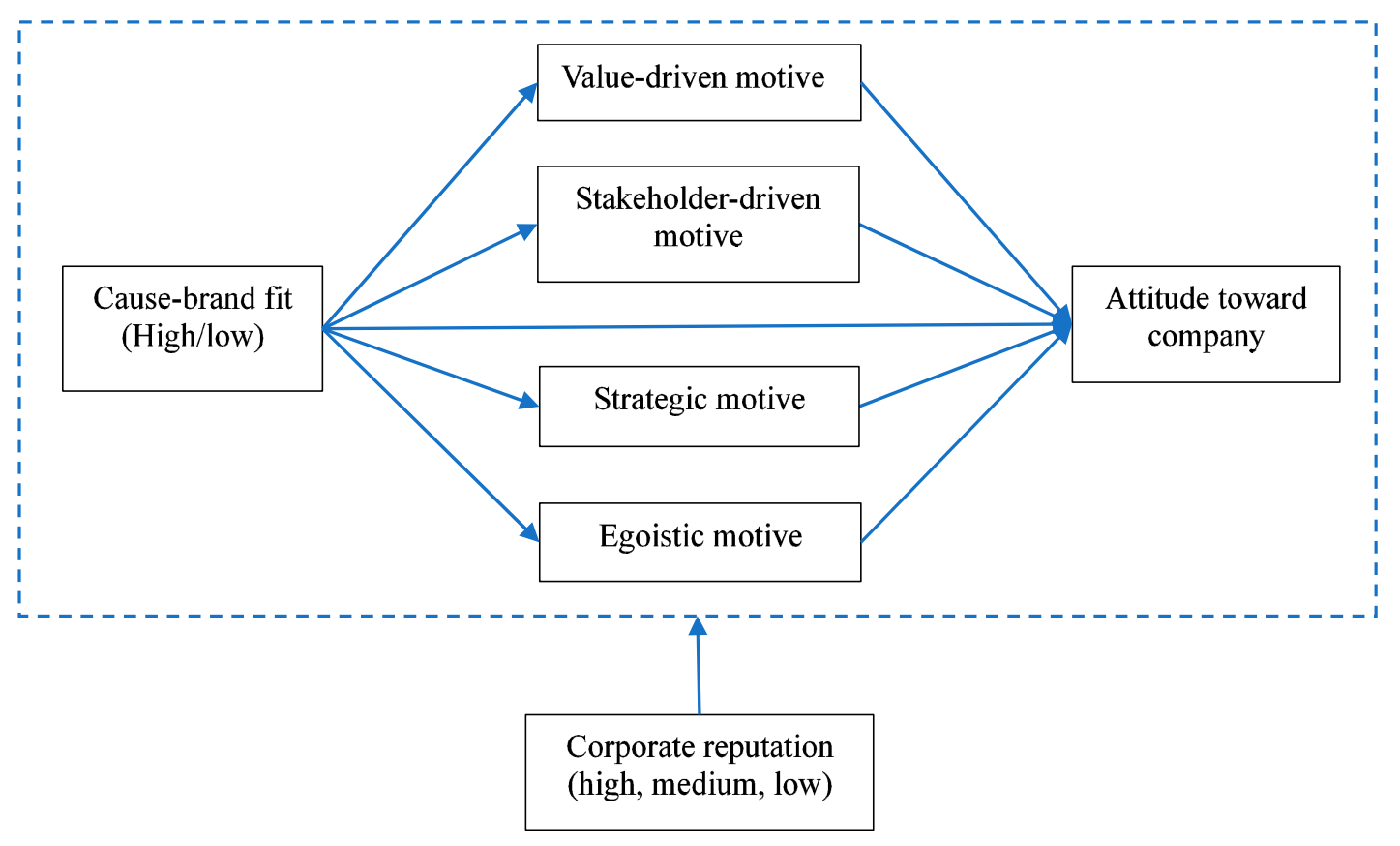

Figure 1. The proposed research model for this study.

\section{Materials and Methods}

\subsection{Experimental Design and Manipulation}

This study intended to explore the effects of cause-brand fit on consumers' attributed motives and attitudes at varying levels (low, medium, and high) of corporate reputation. We adopted a 2 (cause-brand fit: low vs. high) $\times 3$ (corporate reputation: low vs. medium vs. high) experiment with the latter factor within subjects. We manipulated the three levels of corporate reputation (low, medium, and high) with three true companies, which were identified in a pre-test. According to an industry report, seven known Taiwanese food companies (IME, Hey Song, Wei Chuan, Kuang Chuan, UNI, Fresh Delight, and Laurel) were chosen and presented to respondents to rate perceived reputation. With a series of paired-samples $t$-tests, Wei Chuan was selected as a low-reputation company $\left(M_{\text {Wei Chuan }}=2.29\right)$, UNI as a medium-reputation company $\left(M_{\mathrm{UNI}}=4.57\right)$, and IME as a high-reputation company $\left(\mathrm{M}_{\mathrm{IME}}=5.62\right)$. To eliminate the potential confounder of company familiarity, a three-item 7-point Likert scale [80] was used, finding high familiarity (all $M>6$ ), with no significant differences between groups. 
High and low cause-brand fit was manipulated by varying the social causes [81], which were selected in the same pre-test. Consumer Food Safety and Adolescent Education represented the highand low-fitted causes, respectively. For the donation amount for the CRM, we adopted the percentage of sales, which is most used by managers and researched in literature [71]. Given the impact of the donation amount on consumer reactions to CRM, a middle-level donation amount was needed. The pre-test identified $2 \%$ of sales.

\subsection{Procedure and Measures}

Participants were first asked to select their fruit preference between an apple and watermelon. Those who chose apple would enter the low cause-brand fit scenario; the others would enter the high cause-brand fit scenario. Then, we presented each company's name, industrial category (food manufacture), and logo. After that, the respondents were asked to rate corporate reputation according to each of the following four statements on a 7-point Likert scale ( $1=$ strongly disagree; $7=$ strongly agree $)$ (e.g., for IME): (1) "IME is a company I have a good feeling about", (2) "IME is a company that I trust", (3) "IME is a company that I admire and respect", and (4) "IME has a good overall reputation" [82]. Following this, the participants were presented with an example CRM campaign. For example, the IME decided to allocate $2 \%$ of annual sales toward a charity fund to sponsor the social cause "Consumer Food Safety". Then, the respondents were instructed to infer the companies' motivations for developing the CRM program on a 7-point Likert scale (e.g., "They want to make it easier for consumers who care about the cause to support it.") [35]. On the next screen, the respondents were instructed to indicate their attitudes toward the company on a mixed four-item 7-point semantic differential scale anchored by "bad/good", "unfavorable/favorable", "negative/positive", and "dislike/like" [27,73]. Subsequently, the respondents were asked to rate on a three-item 7-point bi-polar scale ("incompatible/compatible", "unbelievable/believable", and "makes no sense/makes sense") to check the manipulation of cause-brand fit [31]. Finally, participants' demographic characteristics were collected, including age, gender, education level, and monthly income (see supplementary file).

\subsection{Data Collection}

Data were collected in Taiwan, China. The questionnaire was originally developed in English and translated into Chinese, before being translated again by two bilingual experts to ensure consistency. An online invitation link to the experiment was placed on PTT (https://www.ptt.cc/index.html), the largest bulletin board system in Taiwan. The participants were told that the aim of the study was to gather opinions on food manufacturers in Taiwan. Individuals who visited the communities and were interested in the content completed the experiment. In addition, the participants were informed that they would be entered into a lottery with a prize of a 16G USB flash disk if their answers were valid. The winners were notified by e-mail.

\section{Results}

\subsection{Participants' Profile}

In total, 293 participants completed the experiment, of which 218 provided valid responses; 110 participants were allocated to the high cause-brand fit condition, and 108, the low cause-brand fit condition. The sample consisted of $38.1 \%$ males and $61.9 \%$ females. The majority of the participants $(91.1 \%)$ were between 18 and 40 years of age; $29.8 \%$ were 19 to 24 years old and 25 to 29 years old, $22.5 \%$ were 30 to 34 years old, and $9.2 \%$ were $35-39$ years old. The education level of more than half $(64.2 \%)$ of the respondents was college (including technological academy), and nearly one third (32.6\%) were master's students. The monthly income of most respondents was TWD 15,000 or below $(31.2 \%)$, TWD 25,001-35,000 (20.2\%), or TWD 35,001-45,000 (20.2\%) (see Table 1). 
Table 1. Respondents' demographic statistics.

\begin{tabular}{lcccccc}
\hline \multirow{2}{*}{ Variable Category } & \multicolumn{2}{c}{ Overall (N = 218) } & \multicolumn{2}{c}{ Low Fit $\mathbf{( N ~ = ~ 1 0 8 ) ~}$} & \multicolumn{2}{c}{ High Fit (N = 110) } \\
\cline { 2 - 7 } & $\mathbf{n}$ & Valid (\%) & $\mathbf{n}$ & Valid (\%) & $\mathbf{n}$ & Valid (\%) \\
\hline Gender & & & & & & \\
Male & 83 & 38.1 & 32 & 29.6 & 51 & 46.4 \\
Female & 135 & 61.9 & 76 & 70.4 & 59 & 53.6 \\
\hline Age & & & & & & \\
18 years old or below & 6 & 2.8 & 4 & 3.7 & 2 & 1.8 \\
19-24 years old & 65 & 29.8 & 36 & 33.3 & 29 & 26.4 \\
25-29 years old & 65 & 29.8 & 32 & 29.6 & 33 & 30.0 \\
30-34 years old & 49 & 22.5 & 22 & 20.4 & 27 & 24.5 \\
35-39 years old & 20 & 9.2 & 11 & 10.2 & 9 & 8.2 \\
40 years old or above & 13 & 6.1 & 3 & 2.8 & 10 & 9.1 \\
\hline Education & & & & & & \\
Senior high school & 5 & 2.3 & 2 & 1.9 & 3 & 2.7 \\
College & 140 & 64.2 & 73 & 67.6 & 67 & 60.9 \\
Master & 71 & 32.6 & 32 & 29.6 & 39 & 35.5 \\
Doctor & 2 & 0.9 & 1 & 0.9 & 1 & 0.9 \\
\hline Monthly income & & & & & & \\
TWD 15,000 or below & 68 & 31.2 & 39 & 36.1 & 29 & 26.4 \\
TWD 15,001-25,000 & 15 & 6.9 & 8 & 7.4 & 7 & 6.4 \\
TWD 25001-35,000 & 44 & 20.2 & 18 & 16.7 & 26 & 23.6 \\
TWD 35,001-45,000 & 44 & 20.2 & 26 & 24.1 & 18 & 16.4 \\
TWD 45,001-55,000 & 25 & 11.5 & 8 & 7.4 & 17 & 15.5 \\
TWD 55,001-65,000 & 13 & 6.0 & 6 & 5.6 & 7 & 6.4 \\
TWD 65,001 or above & 9 & 4.1 & 3 & 2.8 & 6 & 5.4 \\
\hline
\end{tabular}

\subsection{Scale Validation}

The reliability and validity of the scales were tested before checking the manipulation and testing the hypotheses. Because the corporate reputation, cause-brand fit, and consumer attitudes were all measured more than once, all the answers for each variable were combined to assess the adequacy of the scale overall. Reliability tests and confirmatory factor analyses were conducted via SPSS v.26 and AMOS v.26 (see Table 2).

Table 2. Reliability and validity analysis results.

\begin{tabular}{|c|c|c|c|c|c|c|c|}
\hline Construct & Items & Estimate & C. Ratio $^{1}$ & S.E. ${ }^{2}$ & C.R. ${ }^{3}$ & $\operatorname{AVE}^{4}$ & Alpha \\
\hline & Corporate reputation & & & & & & 0.976 \\
\hline CR1 & $\begin{array}{l}\mathrm{X} \text { is a company I have a good feeling } \\
\text { about. }\end{array}$ & 0.966 & & & 0.977 & 0.914 & \\
\hline CR2 & $\mathrm{X}$ is a company that I trust. & 0.967 & 66.771 & 0.015 & & & \\
\hline CR3 & $\begin{array}{l}\mathrm{X} \text { is a company that I admire and } \\
\text { respect. }\end{array}$ & 0.954 & 60.859 & 0.017 & & & \\
\hline CR4 & $\mathrm{X}$ has a good overall reputation. & 0.937 & 54.828 & 0.020 & & & \\
\hline Cause-brand fit & & & & & & & 0.937 \\
\hline FIT1 & Incompatible/compatible & 0.911 & & & 0.938 & 0.834 & \\
\hline FIT2 & Unbelievable/believable & 0.915 & 37.621 & 0.028 & & & \\
\hline FIT3 & Make no sense/makes sense & 0.913 & 37.440 & 0.028 & & & \\
\hline & Attributed motives & & & & & & 0.880 \\
\hline & Other-centered & & & & & & 0.926 \\
\hline & value-driven & & & & 0.893 & 0.735 & 0.892 \\
\hline VDM1 & $\begin{array}{l}\text { They feel morally obligated to help. } \\
\text { They want to make it easier for }\end{array}$ & 0.797 & & & & & \\
\hline VDM4 & $\begin{array}{l}\text { consumers who care about the cause } \\
\text { to support it. }\end{array}$ & 0.884 & 25.654 & 0.042 & & & \\
\hline VDM5 & $\begin{array}{l}\text { They are trying to give something } \\
\text { back to the community. }\end{array}$ & 0.888 & 25.806 & 0.040 & & & \\
\hline
\end{tabular}


Table 2. Cont.

\begin{tabular}{|c|c|c|c|c|c|c|c|}
\hline Construct & Items & Estimate & C. Ratio $^{1}$ & S.E. ${ }^{2}$ & C.R. ${ }^{3}$ & $\operatorname{AVE}^{4}$ & Alpha \\
\hline & Stakeholder-driven & & & & 0.891 & 0.734 & 0.878 \\
\hline SDM1 & They feel their customers expect it. & 0.935 & & & & & \\
\hline SDM2 & $\begin{array}{l}\text { They feel society in general (i.e., } \\
\text { consumers) expect it. }\end{array}$ & 0.897 & 36.030 & 0.026 & & & \\
\hline SDM3 & They feel their stockholders expect it. & 0.723 & 23.426 & 0.036 & & & \\
\hline Self-centered & & & & & & & 0.899 \\
\hline Strategic & & & & & 0.847 & 0.652 & 0.829 \\
\hline SM1 & $\begin{array}{l}\text { They will get more customers by } \\
\text { making this offer. }\end{array}$ & 0.864 & & & & & \\
\hline SM2 & $\begin{array}{l}\text { They will keep more of their } \\
\text { customers by making this offer. }\end{array}$ & 0.873 & 27.104 & 0.036 & & & \\
\hline SM3 & $\begin{array}{l}\text { They hope to increase profits by } \\
\text { making this offer. }\end{array}$ & 0.668 & 18.775 & 0.047 & & & \\
\hline Egoistic & & & & & 0.875 & 0.703 & 0.862 \\
\hline EM1 & $\begin{array}{l}\text { They are taking advantage of the } \\
\text { non-profit organization to help their } \\
\text { own business. }\end{array}$ & 0.868 & & & & & \\
\hline EM2 & $\begin{array}{l}\text { They are taking advantage of the } \\
\text { cause to help their own business. }\end{array}$ & 0.925 & 30.562 & 0.032 & & & \\
\hline EM4 & They want to get publicity. & 0.707 & 20.873 & 0.038 & & & \\
\hline Attitude & & & & & & & 0.983 \\
\hline ATT1 & Bad/good & 0.976 & & & 0.983 & 0.936 & \\
\hline ATT2 & Unfavorable/favorable & 0.966 & 72.166 & 0.014 & & & \\
\hline ATT3 & Negative/positive & 0.968 & 74.075 & 0.014 & & & \\
\hline ATT4 & Dislike/like & 0.960 & 68.792 & 0.015 & & & \\
\hline
\end{tabular}

Notes. VDM: value-driven motive; SDM: stakeholder-driven motive; SM: strategic motive; EM: egoistic motive; ATT: consumer attitudes. Items deleted: VDM2, VDM3, SDM4, EM3. ${ }^{1}:$ C. ratio = critical ratio; ${ }^{2}$ : S.E. = standard error; ${ }^{3}:$ C.R. $=$ composite reliability; ${ }^{4}:$ AVE $=$ average variance extracted.

Indicator reliability was determined by the standard estimate, and the results suggested a high degree of individual item reliability of 0.7 or larger [83]. Cronbach's alpha and composite reliability were both used to measure internal item consistency [84]. The results demonstrated excellent reliability for all four scales (between 0.80 and 0.98) [84]. The convergent validity was assessed through the average variance (AVE). The results indicated adequate validity for all the constructs, as all the AVE values well exceeded $0.5[84,85]$.

\subsection{Manipulation Check}

A series of ANOVAs (Analyses of Variance) were conducted to examine the manipulation of cause-brand fit and corporate reputation. The results indicated that the manipulation for cause-brand fit was successful. There was a significant difference in the means of fit for the two different causes $(F(1,652)=7.891, p<0.01)$. Consumer Food Safety was considered a cause more congruent with the food company $(M=5.02)$ than the Adolescent Education cause $(M=4.70)$. The manipulation check for corporate reputation was also successful. There was a significant difference in the means of corporate reputation for Wei Chuan (low: $M=2.84$ ), UNI (medium: $M=4.39$ ), and IME (high: $M=5.69$ ) $(F(2,651)=272.084, p<0.001)$. Thus, the manipulations were all successful.

\subsection{Hypothesis Testing}

\subsubsection{Structural Model}

We used covariance-based structural equation modeling (SEM) in AMOS to test the causal paths between cause-brand fit, attributed motives, and consumer attitudes. The results showed that the overall fit of the model was good $\left(\chi^{2} / \mathrm{df}=4.706, \mathrm{CFI}=0.961, \mathrm{TLI}=0.953, \mathrm{RFI}=0.941, \mathrm{NFI}=0.951\right.$, and RMSEA = 0.075). In the overall model (Figure 2), there was a significant direct pathway between cause-brand fit and consumer attitudes toward the company (Std. $\beta=0.632, p<0.001$ ), thus supporting hypothesis H1. In addition, cause-brand fit also impacted consumer attitudes through the attributed company's motivation. The cause-brand fit had significant effects across all the four dimensions of 
motivation, particularly value-driven motives (Std. $\beta=0.798, p<0.001$ ), stakeholder-driven motives (Std. $\beta=0.699, p<0.001$ ), strategic motives (Std. $\beta=0.323, p<0.001$ ), and egoistic motives (Std. $\beta=0.090$, $p<0.05$ ). These results supported $\mathrm{H} 2$ but refuted $\mathrm{H} 3$. Furthermore, value-driven motives had a significant positive effect on consumer attitudes (Std. $\beta=0.180, p<0.001$ ), while egoistic motives had a significant negative effect (Std. $\beta=-0.102, p<0.05$ ) on consumer attitudes. Stakeholder-driven motives (Std. $\beta=0.076, p>0.05$ ) and strategic motives (Std. $\beta=-0.074, p>0.05$ ) did not significantly influence consumer attitudes. Thus, $\mathrm{H} 4$ and $\mathrm{H} 5$ were partially supported.

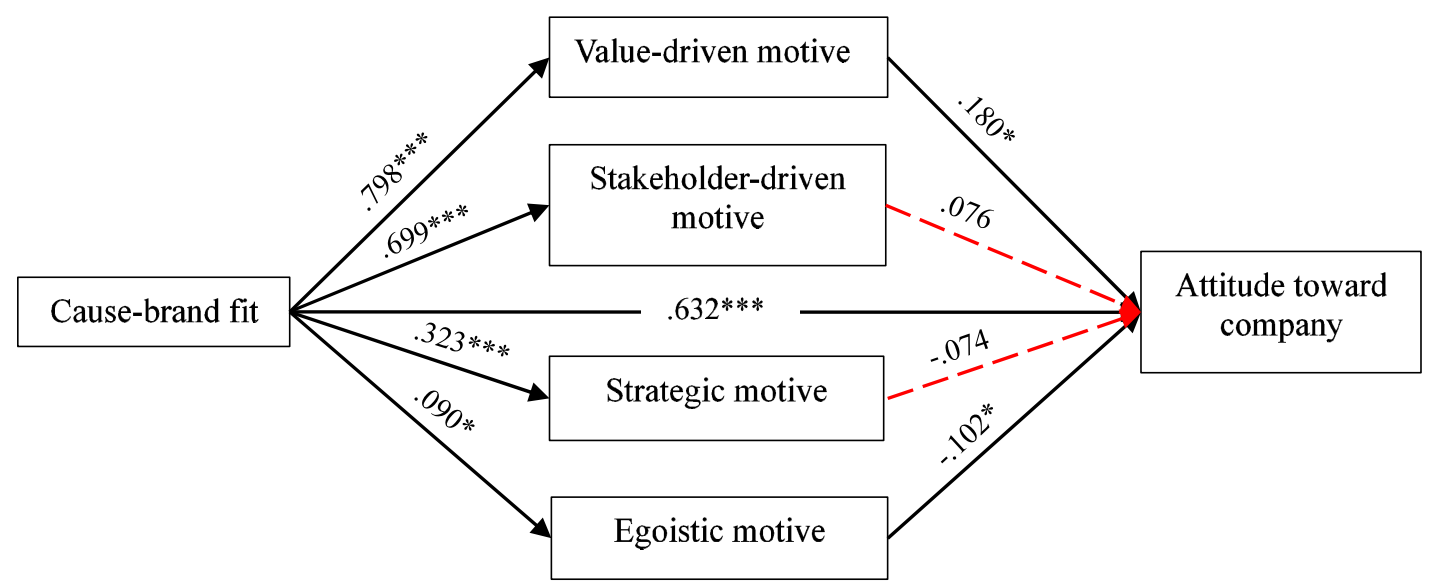

Figure 2. The validated model.

\subsubsection{Moderation}

Multi-group analysis (MGA) was then applied to the model to examine the moderating effect of corporate reputation for both high and low cause-brand fit conditions. Table 3 illustrates the effects (Std. $\beta$ ) of each variable relationship in the model. The results indicated a significant direct pathway between the cause-brand fit and consumer attitudes regardless of the company's reputation or perceived cause-brand fit. However, there were significant differences for the impacts of attributed motives on consumer attitudes when the corporate reputation varied.

When a low-reputation company implemented a CRM program and the cause-brand fit was high, consumer-attributed egoistic motives would further negatively impact their attitudes toward the company (Std. $\beta=-0.204, p<0.05$ ). Meanwhile, stakeholder-driven motives would be prominent and further positively impact consumer attitudes (Std. $\beta=0.436, p<0.01$ ) when the low-reputation company supported a low-fit cause.

There was a completely different result for the medium-reputation company. Specifically, when a medium-reputation company implemented a CRM program and the cause-brand fit was high, consumers would mainly attribute value-driven motives, and it had a positive effect on their attitudes (Std. $\beta=0.504, p<0.001$ ). Meanwhile, the attributed strategic motive would be prominent and further negatively impact consumer company attitudes (Std. $\beta=-0.398, p<0.01$ ) when the medium-reputation company supported a low-fit cause.

For the high-reputation company, consumers mainly inferred its CRM campaign as other centered when it supported a low-fit social cause. Moreover, the value-driven motive (Std. $\beta=0.529, p<0.05$ ) had a significantly positive impact and the stakeholder-driven motive (Std. $\beta=-0.403, p<0.05$ ) had negative effect on consumer attitudes toward the company. When the high-reputation company supported a high-fit social cause, the consumer-attributed strategic motive would further negatively impact their attitudes toward the company (Std. $\beta=-0.301, p<0.05$ ). Taken together, corporate reputation had a significant moderating effect on the effect of cause-brand fit. Thus, hypothesis H6 was supported. 
Table 3. Model path coefficients and multi-group analysis.

\begin{tabular}{|c|c|c|c|c|c|c|c|c|}
\hline \multirow[b]{2}{*}{ Relationships } & \multicolumn{2}{|c|}{ Overall } & \multicolumn{2}{|c|}{ Low Reputation } & \multicolumn{2}{|c|}{ Medium Reputation } & \multicolumn{2}{|c|}{ High Reputation } \\
\hline & Std. $\beta$ & $p$ & Std. $\beta$ & $p$ & Std. $\beta$ & $p$ & Std. $\beta$ & $p$ \\
\hline \multicolumn{9}{|l|}{ Low fit } \\
\hline $\mathrm{FIT} \rightarrow \mathrm{VDM}$ & 0.772 & $* * *$ & 0.740 & $* * *$ & 0.693 & $* * *$ & 0.720 & $* * *$ \\
\hline $\mathrm{FIT} \rightarrow \mathrm{SDM}$ & 0.706 & $* * *$ & 0.606 & $* * *$ & 0.669 & $* * *$ & 0.648 & $* * *$ \\
\hline $\mathrm{FIT} \rightarrow \mathrm{SM}$ & 0.424 & $* * *$ & 0.361 & $0.001^{* *}$ & 0.517 & $* * *$ & 0.543 & $* * *$ \\
\hline $\mathrm{FIT} \rightarrow \mathrm{EM}$ & 0.177 & $* *$ & 0.068 & 0.536 & 0.321 & $0.003^{* *}$ & 0.387 & $* * *$ \\
\hline $\mathrm{VDM} \rightarrow \mathrm{ATT}$ & 0.031 & 0.800 & -0.116 & 0.549 & 0.338 & 0.219 & 0.529 & 0.019 * \\
\hline $\mathrm{SDM} \rightarrow \mathrm{ATT}$ & 0.203 & $0.05 *$ & 0.436 & $0.004^{* *}$ & -0.008 & 0.976 & -0.403 & 0.037 * \\
\hline $\mathrm{SM} \rightarrow \mathrm{ATT}$ & -0.172 & $0.05^{*}$ & -0.105 & 0.509 & -0.398 & $0.009^{* *}$ & 0.321 & 0.135 \\
\hline $\mathrm{EM} \rightarrow \mathrm{ATT}$ & -0.094 & 0.234 & -0.183 & 0.216 & 0.032 & 0.804 & -0.342 & 0.075 \\
\hline $\mathrm{FIT} \rightarrow \mathrm{ATT}$ & 0.667 & $* * *$ & 0.482 & $0.001^{* *}$ & 0.626 & $* * *$ & 0.640 & $* * *$ \\
\hline \multicolumn{9}{|l|}{ High fit } \\
\hline $\mathrm{FIT} \rightarrow \mathrm{VDM}$ & 0.807 & $* * *$ & 0.714 & $* * *$ & 0.845 & $* * *$ & 0.694 & $* * *$ \\
\hline $\mathrm{FIT} \rightarrow \mathrm{SDM}$ & 0.692 & $* * *$ & 0.644 & $* * *$ & 0.654 & $* * *$ & 0.545 & $* * *$ \\
\hline $\mathrm{FIT} \rightarrow \mathrm{SM}$ & 0.259 & $* * *$ & 0.355 & $0.003^{* *}$ & 0.231 & 0.031 * & 0.308 & $0.003^{* *}$ \\
\hline $\mathrm{FIT} \rightarrow \mathrm{EM}$ & 0.029 & 0.623 & 0.063 & 0.546 & 0.060 & 0.546 & 0.189 & 0.068 \\
\hline $\mathrm{VDM} \rightarrow \mathrm{ATT}$ & 0.209 & $0.016^{*}$ & 0.095 & 0.617 & 0.504 & $* * *$ & 0.248 & 0.103 \\
\hline $\mathrm{SDM} \rightarrow \mathrm{ATT}$ & 0.003 & 0.964 & 0.151 & 0.369 & -0.109 & 0.248 & -0.058 & 0.635 \\
\hline $\mathrm{SM} \rightarrow \mathrm{ATT}$ & -0.038 & 0.570 & 0.040 & 0.716 & -0.107 & 0.684 & -0.301 & 0.023 * \\
\hline $\mathrm{EM} \rightarrow \mathrm{ATT}$ & -0.083 & 0.190 & -0.240 & 0.022 * & 0.039 & 0.875 & 0.157 & 0.212 \\
\hline $\mathrm{FIT} \rightarrow \mathrm{ATT}$ & 0.704 & $* * *$ & 0.608 & $* * *$ & 0.500 & $* * *$ & 0.669 & $* * *$ \\
\hline
\end{tabular}

Note. VDM: value-driven motive; SDM: stakeholder-driven motive; SM: strategic motive; EM: egoistic motive; ATT: consumer attitudes. ${ }^{* * *} p<.001 ;{ }^{* *} p<0.01 ;{ }^{*} p<0.05$.

\section{Discussion}

This study sought to provide further evidence of the influence of cause-brand fit and corporate reputation on consumer attitudes and attributed company motives. The results suggested that the cause-brand fit significantly impacted consumer attitudes toward the company directly and through attributed company motives. We also identified the moderating role of corporate reputation. The following section discusses the important practical and theoretical implications of these results in relation to previous studies and the important theoretical and practical implications.

\subsection{The Influence of Cause-Brand Fit}

The congruency between the social cause and the company's business is important for consumer perception, reaction, and the effectiveness of the CRM program. Our results suggested that cause-brand fit positively influenced consumer attitudes toward the company. These findings are similar to those of many previous studies suggesting that a high cause-brand fit for CRM campaigns elicits more positive outcomes such as enhanced brand image [44], brand credibility [28], and purchase intentions [15,27,29]. The positive effect of fit on consumer responses aligns with congruency theory, stating that the more the two entities fit, the better the association and attitudinal outcomes [29].

This positive effect of fit on consumer attitudes is in contrast to Lafferty's (2007) [31] findings, where cause-brand fit had no significant effect on consumer attitude and purchase intentions, regardless of the company's level of reputation. The two causes (Adolescent Education and Consumer Food Safety) in our study belong to two different social fields and adopted neutral expressions. In Lafferty (2007)'s study [31], the high-(Prevention of Cruelty of Animals) and low-(Save the Whales) fit causes belong to one category - animal — and on the other hand, used preventive and promotive framing, respectively. The cause category and framing were both proven to be important factors impacting consumer responses to the company and associated CRM programs [71,86]. Thus, future research could explore the interaction effect of the cause category, cause framing, and cause-brand fit on consumer 
perception and reaction to CRM. Companies should also simultaneously consider cause type and framing when deciding to support a high-fit social cause in CRM.

\subsection{Attributed Company Motives}

The results suggested that consumers deliberately attributed value-driven motives, stakeholder-driven motives, strategic motives, and egoistic motives to companies. That is, consumers made specific inferences about why companies engage in CRM campaigns. This finding aligns with previous studies highlighting several components to consumer-attributed motives [35], as opposed to merely two opposing constructs [14,29].

The results also showed that high cause-brand fit leads to higher positive consumer responses than a low fit. Specifically, a high fit mainly elicited perceived value-driven company motives, whereas a low fit resulted in greater stakeholder-driven and strategic motives. In this way, value-driven motives are known to be more conducive to positive consumer evaluations and purchase behavior, finally leading to success of the CRM efforts [35]. Similarly, previous studies also identified a high cause-brand fit as a precursor to positive motive attribution [30,47]. On the other hand, this result indicated that consumers had simpler attributions for the CRM programs with high cause-brand fit. This further supports the congruency between a low (vs. high) fit and favorable company motives, due to the inconsistencies with consumer expectations [28,29]. From this perspective, companies should adopt a high-fit strategy to reduce consumer skepticism, which may lead to critical thinking about a company's motives [41]. For example, when a Food Company donates money to aid third world countries (high cause-brand fit), consumers would attribute the company's motives as value-driven. However, when a Food Company supports a little-congruent cause such as Save the Wildlife, such inconsistency would raise consumer skepticism about the CRM campaign.

Our study proposed that consumers could make detailed attributions for firms' CRM programs and adopted Ellen et al. (2006)'s [35] scale that divided other-centered motives into value-driven motives and stakeholder-driven motives, and self-centered motives into strategic and egoistic motives. The results suggested that value-driven and stakeholder-driven motives had positive effects, whereas the strategic and egoistic motives had negative effects on consumer attitudes. This is similar to most of the literature (e.g., [29]) that simply considered consumers' inferences as either self- or other-centered motives, and found that the former positively affect and the latter negatively affect further consumer evaluation. However, our finding differs somewhat from Ellen et al. (2006)'s [35] result that value-driven and strategic motives had positive effects while stakeholder-driven and egoistic motives had negative effects on consumers. Looking closer, it is clear that value-driven motives have positive effects and egoistic motives have negative effects on consumer responses. However, there remain widely different results determining the effect of stakeholder-driven and strategic motives. This might be due to cultural differences. Our study was conducted in Taiwan, China, where a collectivist culture is most prevalent. Therefore, this may explain this study's more positive responses when the company's CRM was perceived to satisfy the stakeholders' expectations (i.e., stakeholder-driven motives). The respondents in Ellen et al. (2006)'s [35] research were Americans, who are more individualistic and place companies' economic goals higher than social responsibilities [48]. Therefore, consumers' attributed companies' strategic motives in Ellen et al. (2006) [35] positively impacted consumer attitudes, whereas stakeholder-driven motives negatively influenced attitudes. More studies should be conducted to further examine these motives' effects on consumer responses and explore the effect of culture (collectivism vs. individualism). On the other hand, companies should design CRM campaigns based on the target market's culture and consumers' self-construal, so as to elicit the targeted consumers' positive reaction and then better achieve economic and social sustainability.

\subsection{Corporate Reputation}

Our results suggested the moderating role of corporate reputation has an effect on cause-brand fit and consumer-attributed company motives. For the company with a low reputation, a low cause-brand 
fit CRM program led to consumer-attributed stakeholder-driven motives, which had positive effects on consumer attitudes toward the company. Meanwhile a high-fit CRM campaign of a low-reputation company resulted in egoistic company motives, which negatively influenced attitudes. That is, the low-reputation companies could benefit from a low-fit CRM campaign, but a high-fit CRM would harm the low-reputation companies. This finding aligns with Yoon et al. (2006) [46], who found that a high cause-brand fit strategy would yield reverse effects for low-reputation companies. It is worth noting that the companies' low reputation in Yoon et al. (2006) [46] was manipulated with low-reputation industries (i.e., tobacco and oil). Our study extends their results, where even a low-reputation company in a neutral industry (e.g., a food company) reveals the same effects. Thus, low- or bad-reputation companies should avoid adopting high cause-brand fit CRM strategies. Rather, supporting a low-fit social cause in CRM would be accepted by consumers, and the low-reputation companies would ultimately benefit.

Interestingly, the opposite result was found for the medium-reputation company. Specifically, medium-reputation companies were shown to benefit from high-fit CRM campaigns due to consumers attributing value-driven company motives, whereas a low cause-brand fit would harm the medium-reputation company because it resulted in consumers attributing strategic motives, which negatively impact consumer attitudes toward companies. This finding is in contrast to the findings of Elving (2013) [41], who found that companies with medium reputation could gain positive outcomes regardless of the fit. The stimuli in Elving (2013)'s [41] study were fictitious companies, manipulated by presenting participants a paragraph of textual information. In the case of the current study, we adopted true companies, which increased the external validity. On the other hand, the familiarity that the participants had with the true companies may have impacted the results. Future research could further explore the moderating effect of familiarity against novelty. Companies should also note the familiarity that consumers have with them when designing CRM campaigns.

For the high-reputation company, there were negative attributed motives for both the high and low cause-brand fit scenarios. Specifically, a high cause-brand fit CRM campaign by the high-reputation companies resulted in consumer-attributed strategic motives, which negatively impacted consumer attitudes toward the company. This is different from Elving (2013)'s [41] results showing that there was the lowest level of skepticism for a good reputation and good cause-brand fit. In addition, when a high-reputation company engaged in a low-fit CRM campaign, consumers would infer value-driven and stakeholder-driven motives. Moreover, consumers attributed stakeholder-driven motives to the high-reputation company, which negatively impacted attitudes. These results differ from those for the low- and medium-reputation companies. One explanation may be the high expectations that consumers have for high-reputation companies [87]. That is, high-reputation companies should make more contributions and/or take more responsibility for environmental and social sustainability. Thus, high-reputation companies should make more efforts to satisfy consumers' higher CSR expectations, improving consumer satisfaction and favorable consumer responses, such as loyalty and word of mouth.

\section{Conclusions}

CRM could benefit companies and society simultaneously when it elicits positive consumer responses, which contribute to sustainability. Environmental, social, and economic sustainability are three major dimensions of sustainability [88]. Environmental and social sustainability could be achieved by supporting environmental (e.g., climate change) and social causes (e.g., disaster relief) in CRM, while economic sustainability would be achieved when consumers responded positively to the company.

Based on this study's results, we confirm that both the cause-brand fit and the perceived company reputation per se have important implications for consumer evaluations of CRM efforts and, ultimately, behavior. There is no absolute answer for "Which one is better: high or low cause-brand fit?" because of the moderating effect of corporate reputation. Low-reputation companies could achieve positive 
outcomes by engaging in a low cause-brand fit CRM campaign, while a high-fit strategy would harm it. The opposite is true for the medium-reputation companies. That is, medium-reputation companies could achieve positive outcomes by engaging in a high cause-brand fit CRM campaign, while a low-fit strategy would hurt it. The high-reputation companies need to make more efforts to achieve positive consumer responses because of consumers' high expectations of them. Therefore, companies should choose the social causes carefully based on their own business and reputation to better achieve economic sustainability while making contributions to environmental and social sustainability.

In addition, the moderating role of corporate reputation revealed that perceived company motives seemed to depend on how consumers viewed their place in society. High-reputation companies may hold greater power or wealth and, therefore, are seen to be more socially responsible than smaller companies, who may be perceived as, due to their size, "allowed" to have more self-driven motives. As corporate entities gather more and more wealth compared to public bodies and governments, their perceived responsibilities to social causes involving the environment and society also increase. In other words, high-reputation companies should assume more social responsibility to social and environmental sustainability than smaller ones. Medium- and low-reputation companies could firstly improve their own economic sustainability and then be able to contribute more to environmental and social sustainability through CRM campaigns.

Supplementary Materials: The following are available online at http://www.mdpi.com/2071-1050/12/20/8338/s1. Table S1: The questionnaire for the experiment.

Author Contributions: Conceptualization, A.Z., H.-Y.L., and B.P.; methodology, A.Z. and H.-Y.L.; software, A.Z.; validation, A.Z.; formal analysis, A.Z.; investigation, A.Z.; data curation, A.Z. and B.P.; writing-original draft preparation, A.Z., A.S., and B.P.; writing - review and editing, A.Z., A.S., and B.P.; visualization, A.Z.; supervision, B.P.; project administration, A.Z.; funding acquisition, Z.X. All authors have read and agreed to the published version of the manuscript.

Funding: This research received no external funding.

Acknowledgments: The authors would like to thank all the participants who agreed to fill in the questionnaire.

Conflicts of Interest: The authors declare no conflict of interest.

\section{References}

1. Kramer, M.R.; Porter, M. Creating shared value. In Managing Sustainable Business; Smith, C., Gilbert, G., Lenssen, G., Eds.; Springer: Berlin/Heidelnerg, Germany, 2011; pp. 323-346.

2. Nazzaro, C.; Lerro, M.; Marotta, G. Assessing parental traits affecting children's food habits: An analysis of the determinants of responsible consumption. Agric. Food Econ. 2018, 6, 1-14. [CrossRef]

3. Low, M.P. Corporate social responsibility and the evolution of internal corporate social responsibility in 21st century. Asian J. Soc. Sci. Manag. Stud. 2016, 3, 56-74. [CrossRef]

4. Wang, H.; Tong, L.; Takeuchi, R.; George, G. Corporate social responsibility: An overview and new research directions: Thematic issue on corporate social responsibility. Acad. Manag. J. 2016, 59, 534-544. [CrossRef]

5. Schultz, W. Behavioral theories and the neurophysiology of reward. Annu. Rev. Psychol. 2006, 57, 87-115. [CrossRef]

6. Du, S.; Bhattacharya, C.B.; Sen, S. Reaping relational rewards from corporate social responsibility: The role of competitive positioning. Int. J. Res. Mark. 2007, 24, 224-241. [CrossRef]

7. Varadarajan, P.R.; Menon, A. Cause-related marketing: A coalignment of marketing strategy and corporate philanthropy. J. Mark. 1988, 52, 58-74. [CrossRef]

8. Heller, G.J.; Hechtman, J.A. Corporate sponsorships of sports and entertainment events: Considerations in drafting a sponsorship management agreement. Marq. Sports L. Rev. 2000, 11, 23.

9. Shree, D.; Gupta, A.; Sagar, M. Effectiveness of cause-related marketing for differential positioning of market entrant in developing market: An exploratory study in indian context. Int. J. Nonprofit Volunt. Sect. Mark. 2017, 22, 1-13. [CrossRef]

10. Ross, J.K.; Stutts, M.A.; Patterson, L. Tactical considerations for the effective use of cause-related marketing. J. Appl. Bus. Res. 1991, 7, 58-65. [CrossRef] 
11. Hanzaee, K.H.; Sadeghian, M.; Jalalian, S. Which can affect more? Cause marketing or cause-related marketing. J. Islam. Mark. 2019, 10, 304-322. [CrossRef]

12. Strahilevitz, M. The effects of prior impressions of a firm's ethics on the success of a cause-related marketing campaign: Do the good look better while the bad look worse? J. Nonprofit Public Sect. Mark. 2003, 11, 77-92. [CrossRef]

13. Vanhamme, J.; Lindgreen, A.; Reast, J.; Van Popering, N. To do well by doing good: Improving corporate image through cause-related marketing. J. Bus. Ethics 2012, 109, 259-274. [CrossRef]

14. Kuo, A.; Rice, D.H. The impact of perceptual congruence on the effectiveness of cause-related marketing campaigns. J. Consum. Psychol. 2015, 25, 78-88. [CrossRef]

15. Lafferty, B.A.; Lueth, A.K.; McCafferty, R. An evolutionary process model of cause-related marketing and systematic review of the empirical literature. Psychol. Mark. 2016, 33, 951-970. [CrossRef]

16. Thomas, S.; Kureshi, S.; Vatavwala, S. Cause-related marketing research (1988-2016): An academic review and classification. J. Nonprofit Public Sect. Mark. 2019, 15, 1-29. [CrossRef]

17. Guerreiro, J.; Rita, P.; Trigueiros, D. A text mining-based review of cause-related marketing literature. J. Bus. Ethics 2016, 139, 111-128. [CrossRef]

18. Webb, D.J.; Mohr, L.A. A typology of consumer responses to cause-related marketing: From skeptics to socially concerned. J. Public Policy Mark. 1998, 17, 226-238. [CrossRef]

19. Till, B.D.; Nowak, L.I. Toward effective use of cause-related marketing alliances. J. Prod. Brand Manag. 2000, 9, 472-484. [CrossRef]

20. Hartmann, M.; Klink, J.; Simons, J. Cause related marketing in the german retail sector: Exploring the role of consumers' trust. Food Policy 2015, 52, 108-114. [CrossRef]

21. Pergelova, A.; Angulo-Ruiz, L.F. Marketing and corporate social performance: Steering the wheel towards marketing's impact on society. Soc. Bus. 2013, 3, 201-224. [CrossRef]

22. Strizhakova, Y.; Coulter, R.; Price, L. Responses of global citizens to cause-related green marketing. J. Int. Mark. 2010, 16, 57-85. [CrossRef]

23. Habel, J.; Schons, L.M.; Alavi, S.; Wieseke, J. Warm glow or extra charge? The ambivalent effect of corporate social responsibility activities on customers' perceived price fairness. J. Mark. 2016, 80, 84-105. [CrossRef]

24. Melero, I.; Montaner, T. Cause-related marketing: An experimental study about how the product type and the perceived fit may influence the consumer response. Eur. J. Manag. Bus. Econ. 2016, 25, 161-167. [CrossRef]

25. Witek, L. Influence of socio-demographic characteristics of consumers on attitudes towards cause related marketing. Acta Univ. Agric. Silv. Mendel. Brun. 2016, 64, 2173-2182. [CrossRef]

26. Bhattacharya, C.B.; Sen, S. Doing better at doing good: When, why, and how consumers respond to corporate social initiatives. Calif. Manag. Rev. 2004, 47, 9-24. [CrossRef]

27. Nan, X.; Heo, K. Consumer responses to corporate social responsibility (csr) initiatives: Examining the role of brand-cause fit in cause-related marketing. J. Advert. 2007, 36, 63-74. [CrossRef]

28. Becker-Olsen, K.L.; Cudmore, B.A.; Hill, R.P. The impact of perceived corporate social responsibility on consumer behavior. J. Bus. Res. 2006, 59, 46-53. [CrossRef]

29. Chang, C.T.; Chen, P.C.; Chu, X.Y.; Kung, M.T.; Huang, Y.F. Is cash always king? Bundling product-cause fit and product type in cause-related marketing. Psychol. Mark. 2018, 35, 990-1009. [CrossRef]

30. Sabri, O. The detrimental effect of cause-related marketing parodies. J. Bus. Ethics 2018, 151, 517-537. [CrossRef]

31. Lafferty, B.A. The relevance of fit in a cause-brand alliance when consumers evaluate corporate credibility. J. Bus. Res. 2007, 60, 447-453. [CrossRef]

32. Lafferty, B.A. Selecting the right cause partners for the right reasons: The role of importance and fit in cause-brand alliances. Psychol. Mark. 2009, 26, 359-382. [CrossRef]

33. Bloom, P.N.; Hoeffler, S.; Keller, K.L.; Meza, C.E.B. How social-cause marketing affects consumer perceptions. MIT Sloan Manag. Rev. 2006, 47, 49-55.

34. Drumwright, M.E. Company advertising with a social dimension: The role of noneconomic criteria. J. Mark. 1996, 60, 71-87. [CrossRef]

35. Ellen, P.S.; Webb, D.J.; Mohr, L.A. Building corporate associations: Consumer attributions for corporate socially responsible programs. J. Acad. Mark Sci. 2006, 34, 147-157. [CrossRef]

36. Park, J.; Lee, H.; Kim, C. Corporate social responsibilities, consumer trust and corporate reputation: South korean consumers' perspectives. J. Bus. Res. 2014, 67, 295-302. [CrossRef] 
37. Van Marrewijk, M.; Werre, M. Multiple levels of corporate sustainability. J. Bus. Ethics 2003, 44, 107-119. [CrossRef]

38. Lii, Y.-S.; Lee, M. Doing right leads to doing well: When the type of csr and reputation interact to affect consumer evaluations of the firm. J. Bus. Ethics 2012, 105, 69-81. [CrossRef]

39. Brown, T.J.; Dacin, P.A. The company and the product: Corporate associations and consumer product responses. J. Mark. 1997, 61, 68-84. [CrossRef]

40. Bae, J.; Cameron, G.T. Conditioning effect of prior reputation on perception of corporate giving. Public Relat. Rev. 2006, 32, 144-150. [CrossRef]

41. Elving, W.J.L. Scepticism and corporate social responsibility communications: The influence of fit and reputation. J. Mark Commun. 2013, 19, 277-292. [CrossRef]

42. Stanaland, A.J.S.; Lwin, M.O.; Murphy, P.E. Consumer perceptions of the antecedents and consequences of corporate social responsibility. J. Bus. Ethics 2011, 102, 47-55. [CrossRef]

43. Sen, S.; Du, S.; Bhattacharya, C.B. Corporate social responsibility: A consumer psychology perspective. Curr. Opin. Psychol. 2016, 10, 70-75. [CrossRef]

44. Barone, M.J.; Miyazaki, A.D.; Taylor, K.A. The influence of cause-related marketing on consumer choice: Does one good turn deserve another? J. Acad. Mark. Sci. 2000, 28, 248-262. [CrossRef]

45. Mohr, L.A.; Eroğlu, D.; Ellen, P.S. The development and testing of a measure of skepticism toward environmental claims in marketers' communications. J. Consum. Aff. 1998, 32, 30-55. [CrossRef]

46. Yoon, Y.; Gürhan-Canli, Z.; Schwarz, N. The effect of corporate social responsibility (csr) activities on companies with bad reputations. J. Consum. Psychol. 2006, 16, 377-390. [CrossRef]

47. Folse, J.A.G.; Niedrich, R.W.; Grau, S.L. Cause-relating marketing: The effects of purchase quantity and firm donation amount on consumer inferences and participation intentions. J. Retail. 2010, 86, 295-309. [CrossRef]

48. Forehand, M.R.; Grier, S. When is honesty the best policy? The effect of stated company intent on consumer skepticism. J. Consum. Psychol. 2003, 13, 349-356.

49. Gao, Y.L.; Mattila, A.S. Improving consumer satisfaction in green hotels: The roles of perceived warmth, perceived competence, and csr motive. Int. J. Hosp. Manag. 2014, 42, 20-31. [CrossRef]

50. Myers, B.; Kwon, W.S. A model of antecedents of consumers' post brand attitude upon exposure to a cause-brand alliance. Int. J. Nonprofit Volunt. Sect. Mark. 2013, 18, 73-89. [CrossRef]

51. Skarmeas, D.; Leonidou, C.N. When consumers doubt, watch out! The role of csr skepticism. J. Bus. Res. 2013, 66, 1831-1838.

52. Skarmeas, D.; Leonidou, C.N.; Saridakis, C. Examining the role of csr skepticism using fuzzy-set qualitative comparative analysis. J. Bus. Res. 2014, 67, 1796-1805. [CrossRef]

53. Carroll, A.B. Corporate social responsibility: Evolution of a definitional construct. Bus. Soc. 1999, 38, $268-295$. [CrossRef]

54. Kim, E.K. Consumer Perceptions of Green Cause-Related Marketing (crm) Price Fairness. Ph.D. Thesis, The Pennsylvania State University, State College, PA, USA, 2011.

55. Kim, Y.J.; Lee, W.-N. Overcoming consumer skepticism in cause-related marketing: The effects of corporate social responsibility and donation size claim objectivity. J. Promot. Manag. 2009, 15, 465-483. [CrossRef]

56. Kim, S.-B.; Kim, K.J.; Kim, D.-Y. Exploring the effective restaurant crm ad. Int. J. Contemp. Hosp. Manag. 2016, 28, 2473-2492. [CrossRef]

57. Hamby, A. One for me, one for you: Cause-related marketing with buy-one give-one promotions. Psychol. Mark. 2016, 33, 692-703. [CrossRef]

58. He, H.; Zhu, W.; Gouran, D.; Kolo, O. Moral identity centrality and cause-related marketing. Eur. J. Mark. 2016, 50, 236-259. [CrossRef]

59. Bigné-Alcañiz, E.; Currás-Pérez, R.; Ruiz-Mafé, C.; Sanz-Blas, S. Consumer behavioural intentions in cause-related marketing. The role of identification and social cause involvement. Int. Rev. Public Nonprofit Mark. 2010, 7, 127-143.

60. Chaney, I.; Dolli, N. Cause related marketing in new zealand. Int. J. Nonprofit Volunt. Sect. Mark. 2001, 6, 156-163. [CrossRef]

61. Pracejus, J.W.; Olsen, G.D. The role of brand/cause fit in the effectiveness of cause-related marketing campaigns. J. Bus. Res. 2004, 57, 635-640. [CrossRef] 
62. Youn, S.; Kim, H. Antecedents of consumer attitudes toward cause-related marketing. J. Advert. Res. 2008, 48, 123-137. [CrossRef]

63. Galan-Ladero, M.M.; Galera-Casquet, C.; Valero-Amaro, V.; Barroso-Mendez, M.J. Sustainable, socially responsible business: The cause-related marketing case. A review of the conceptual framework. J. Secur. Sustain. Issues 2013, 2, 35-46. [CrossRef]

64. Ajzen, I. The theory of planned behavior. Organ. Behav. Hum. Decis. Process. 1991, 50, 179-211. [CrossRef]

65. Aaker, D.A.; Biel, A.L. Brand equity and advertising: An overview. In In Brand Equity E Advertising: Advertising's Role in Building Strong Brands; Aaker, D.A., Biel, A.L., Eds.; Lawrence Erlbaum Associates: Hillsdale, Australia, 1993; pp. 1-10.

66. del Mar García-De los Salmones, M.; Perez, A. Effectiveness of csr advertising: The role of reputation, consumer attributions, and emotions. Corp. Soc. Responsib. Environ. Manag. 2018, 25, 194-208. [CrossRef]

67. Rozin, P.; Royzman, E.B. Negativity bias, negativity dominance, and contagion. Pers. Soc. Psychol. Rev. 2001, 5, 296-320. [CrossRef]

68. Skowronski, J.J.; Carlston, D.E. Negativity and extremity biases in impression formation: A review of explanations. Psychol. Bull. 1989, 105, 131-142. [CrossRef]

69. Trimble, C.S.; Rifon, N.J. Consumer perceptions of compatibility in cause-related marketing messages. Int. J. Nonprofit Volunt. Sect. Mark. 2006, 11, 29-47. [CrossRef]

70. Lerro, M.; Raimondo, M.; Stanco, M.; Nazzaro, C.; Marotta, G. Cause related marketing among millennial consumers: The role of trust and loyalty in the food industry. Sustainability 2019, 11, 535. [CrossRef]

71. Chang, C.-T. Missing ingredients in cause-related advertising: The right formula of execution style and cause framing. Int. J. Advert. 2012, 31, 231-256. [CrossRef]

72. Thomas, M.L.; Fraedrich, J.P.; Mullen, L.G. Successful cause-related marketing partnering as a means to aligning corporate and philanthropic goals: An empirical study. Acad. Mark. Stud. J. 2011, 15, 113-132.

73. Simmons, C.J.; Becker-Olsen, K.L. Achieving marketing objectives through social sponsorships. J. Mark. 2006, 70, 154-169. [CrossRef]

74. Bigné, E.; Currás-Pérez, R.; Aldás-Manzano, J. Dual nature of cause-brand fit: Influence on corporate social responsibility consumer perception. Eur. J. Mark. 2012, 46, 575-594. [CrossRef]

75. Kelley, H.H. The processes of causal attribution. Am. Psychol. 1973, 28, 107-128. [CrossRef]

76. Koschate-Fischer, N.; Huber, I.V.; Hoyer, W.D. When will price increases associated with company donations to charity be perceived as fair? J. Acad. Mark. Sci. 2016, 44, 608-626. [CrossRef]

77. Hemingway, C.A.; Maclagan, P.W. Managers' personal values as drivers of corporate social responsibility. J. Bus. Ethics 2004, 50, 33-44. [CrossRef]

78. Chen, Z.; Huang, Y. Cause-related marketing is not always less favorable than corporate philanthropy: The moderating role of self-construal. Int. J. Res. Mark. 2016, 33, 868-880. [CrossRef]

79. Fombrun, C. Reputation: Realizing value from the corporate image. Acad. Manag. Exec. 1996, 10, 99-101.

80. Lafferty, B.A.; Edmondson, D.R. A note on the role of cause type in cause-related marketing. J. Bus. Res. 2014, 67, 1455-1460. [CrossRef]

81. Das, N.; Guha, A.; Biswas, A.; Krishnan, B. How product-cause fit and donation quantifier interact in cause-related marketing (crm) settings: Evidence of the cue congruency effect. Mark. Lett. 2016, 27, 295-308. [CrossRef]

82. Ponzi, L.J.; Fombrun, C.J.; Gardberg, N.A. Reptrak ${ }^{\mathrm{TM}}$ pulse: Conceptualizing and validating a short-form measure of corporate reputation. Corp. Reput. Rev. 2011, 14, 15-35. [CrossRef]

83. Nunnally, J.C. Psychometric Theory, 2nd ed.; Mcgraw Hill: New York, NY, USA, 1978.

84. Fornell, C.; Larcker, D.F. Structural equation models with unobservable variables and measurement error: Algebra and statistics. J. Mark. Res. 1981, 18, 382-388. [CrossRef]

85. Bagozzi, R.P.; Yi, Y. On the evaluation of structural equation models. J. Acad. Mark. Sci. 1988, 16, 74-94. [CrossRef]

86. Cui, Y.; Trent, E.S.; Sullivan, P.M.; Matiru, G.N. Cause-related marketing: How generation y responds. Int. J. Retail Distrib. Manag. 2003, 31, 310-320. [CrossRef] 
87. Kim, S. The process model of corporate social responsibility (csr) communication: Csr communication and its relationship with consumers' csr knowledge, trust, and corporate reputation perception. J. Bus. Ethics 2019, 154, 1143-1159. [CrossRef]

88. Christofi, M.; Leonidou, E.; Vrontis, D. Cause-related marketing, product innovation and extraordinary sustainable leadership: The role towards sustainability. Glob. Bus. Econ. Rev. 2015, 17, 93-111. [CrossRef]

(C) 2020 by the authors. Licensee MDPI, Basel, Switzerland. This article is an open access article distributed under the terms and conditions of the Creative Commons Attribution (CC BY) license (http://creativecommons.org/licenses/by/4.0/). 